\title{
Effect of literacy on family planning practices among married women in rural south India
}

\author{
Rizwan S A. ${ }^{1}$, Ankita Kankaria', Ronald K. Roy ${ }^{2}$, Ravi P. Upadhyay ${ }^{3}$, Palanivel C. ${ }^{4}$, \\ Vinoth Gnana Chellaiyan ${ }^{3}$ and Surendra Babu D. ${ }^{1}$ \\ ${ }^{1}$ MBBS. Resident, Centre for Community Medicine, All India Institute of Medical Sciences, New Delhi, India \\ ${ }^{2}$ MBBS. Resident, Madurai Medical College, Madurai, Tamilnadu, India \\ ${ }^{3} \mathrm{MD}$. Resident, Department of Community Medicine, Vardhman Mahavir Medical College and Safdarjang Hospital, New Delhi, India \\ ${ }^{4} \mathrm{MD}$. Assistant Professor, Indira Gandhi Medical College and Research Institute, Puducherry, India
}

Submission Date: 2-7-2012; Review Completed: 22-7-2012; Accepted Date: 28-7-2012

\section{A BSTRACT}

Background and Aim: Few studies in India have tried to examine the role of female literacy on contraception usage. This study aimed to determine family planning related knowledge and practices and their association with female literacy. Materials and methods: Facility based cross-sectional study was done among married women aged 15-45 years attending outpatient department of three primary health centres in rural Tamilnadu. Data were collected using pretested semistructured questionnaire by a convenience sampling technique. To assess family planning related knowledge, a composite score was calculated and final score was categorised into satisfactory and unsatisfactory. Results: A total of 100 women participated. Fifty nine percent had satisfactory Family Planning related Knowledge and practices (FPK). Contraception prevalence rate for modern methods was $60 \%$. Eighty percent had ever undergone abortions and among them, one fifth had undergone uncertified abortions. With increase in the literacy status, proportion having satisfactory family planning related knowledge increased $(p<0.001)$ and the parity decreased $(p<0.001)$. More literate women were using contraception, had undergone sterilization, had undergone certified abortions and had less male child preference compared to illiterate women. Conclusion: This study offers evidence that promotion of female literacy could be considered a strategy for promoting contraceptive usage and addressing population growth in India.

Keywords: Family planning, Contraception, Female literacy, Facility based study, India

\section{INTRODUCTION}

India is the second most populous country in the world with more than a billion people, second only to China. India is committed to stabilise its population growth over

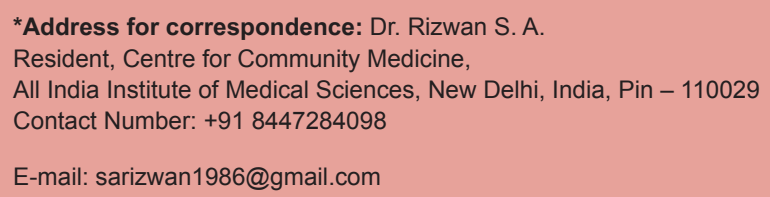

DOI: 10.5530/ijmedph.2.4.5 the next 50 years by achieving a Net Reproduction Rate of 1 through a couple protection rate of atleast $65 \%$ as embodied in the National Population Policy. ${ }^{1}$ Also, the National Rural Health Mission aims at achieving a Total Fertility Rate of 2.1 towards meeting the same end. In this regard the Government of India is providing a wide range of family planning services for free in all public health institutions. In addition to providing free services, distal factors like female literacy which have an important role in achieving population goals have often been ignored. Few studies in India have documented the role of female literacy in the promotion of contraceptive practices. Keeping 
this in context this study aimed to determine the prevalence of self-reported contraceptive usage, to assess Family Planning related Knowledge and practices (FPK) and to study their association with literacy among married women attending Out Patient Departments (OPD) of three Primary Health Centres (PHC) in rural Tamilnadu, India.

\section{MATERIALS AND METHODS}

This study was done in programme mode as an on-going routine activity. Permission was obtained from Medical Officer In-charge of the PHCs to conduct the study. Ethical principles of the Helsinki Declaration were fully complied with and confidentiality of information collected was given high priority. Informed verbal consent was obtained from all participants included in the study. This was a facility based cross-sectional study done among married women attending OPDs of three PHCs namely Kallanthiri, Chekkanoorni, and Poovandi in the district of Madurai in Tamilnadu during December 2009. Tamilnadu located in the south-eastern part of the country is the sixth largest state in India. Madurai, a district located in the southern part of Tamilnadu on the banks of river Vaigai has a total population of about 3 million. Each PHC covers a population of about thirty to forty thousand with an average daily OPD attendance of 150 of which women constitute nearly half. Data were collected using pretested semi-structured questionnaire that contained questions on socio-demographics, contraception usage and other family planning related practices by convenience sampling technique. The socioeconomic status was measured by Modified Prasad's Classification which takes into account per capita income of the family members and contains 6 classes with I being the highest and VI being the lowest class. ${ }^{2}$ Assuming the prevalence of contraceptive usage to be $50 \%$, for a power of $80 \%$, alpha error of $5 \%$, and an absolute precision of $10 \%$, the sample size was calculated as 100. Married women in the reproductive age group i.e., 15-45 years were eligible for inclusion in the study. Women who visited the PHC for purposes of attending the OPD were assessed for eligibility according to the inclusion and exclusion criteria. Eligible women were then requested for consent to participate in the study and questionnaire was administered to the consenting women. To assess the FPK, a composite score was calculated based on 5 variables namely 1. A wareness about contraception methods, 2. Correct knowledge about ideal number of children for a couple, 3. Correct knowledge about ideal birth spacing interval,
4. Correct knowledge about anemia and its importance in pregnancy and 5 . Interval between last 2 children being $\geq 2$ years (only for women with more than 2 children). The final score was categorised into satisfactory and unsatisfactory based on a cut-off of $80 \%$ of the maximum possible score (which was 5 for women with one child and 6 for women with more than one child).

\section{STATISTICAL ANALYSIS}

Statistical analysis was done using statistical software Epi Info 7. Prevalence figures are given as percentages with 95\% confidence intervals wherever necessary. Significance tests like chi square test for difference in proportions and chi square test for trend were applied wherever applicable and a $\mathrm{p}$ value of less than 0.05 was considered significant.

\section{RESULTS}

A total of 100 women were included in the study. About half the women were in the age group of 26 to 35 years and $80 \%$ belonged to social class V and VI. Nearly two-thirds were literate and $70 \%$ had 2 or more children (Table 1).

Family planning related knowledge and practices: Fifty nine percent of the women had satisfactory FPK. It was observed that as the literacy status increased from being illiterate to having $>5$ years of schooling, the proportion of women who had satisfactory FPK also increased (chi square test for trend $\left.\chi^{2}=59.8 ; \mathrm{p}<0.001\right)$ (data not shown). Sixty percent of them had used or were currently using modern methods of contraception (sterilization, pill, IUD, injectables, condom). Among women with 2 or more children, nearly two thirds

\begin{tabular}{|c|c|c|}
\hline \multicolumn{2}{|c|}{ Variables } & \multirow{2}{*}{$\begin{array}{c}\text { Percent } \\
41\end{array}$} \\
\hline Age group & $15-25$ & \\
\hline \multirow[t]{2}{*}{ (years) } & $26-35$ & 51 \\
\hline & $36-45$ & 8 \\
\hline \multirow[t]{3}{*}{ Social Class } & IV & 20 \\
\hline & V & 40 \\
\hline & VI & 40 \\
\hline \multirow[t]{3}{*}{ Literacy } & Illiterate & 37 \\
\hline & $\begin{array}{c}1-5 \text { years of } \\
\text { schooling }\end{array}$ & 15 \\
\hline & $\begin{array}{c}>5 \text { years of } \\
\text { schooling }\end{array}$ & 48 \\
\hline \multirow[t]{2}{*}{ No. of children } & Single child & 30 \\
\hline & $\geq 2$ children & 70 \\
\hline
\end{tabular}


had undergone sterilisation. Eighty percent of the women had ever undergone abortions (including both spontaneous and induced) and among them nearly one fifth had undergone uncertified abortions (for the most recent abortion). Fifty nine percent of women said that they would prefer to have a male child rather than a female child. Significantly, more literate women had satisfactory FPK, were using contraception, had undergone sterilization, had undergone certified abortions and had less male child preference as compared to illiterate women. There was no marked difference between the two groups in having undergone abortions (Table 2).

Reasons for non-use of contraception: Among the 40 women who had never used any contraceptive method, the two most common reasons given for non-use were fear about the methods $(18 / 40,45 \%)$ and family constraints $(17 / 40,43 \%)$, followed by inaccessibility $(2 / 40,5 \%)$ and other reasons like dislike and side effects (3/40, 7\%).

Relation between literacy and parity: Ninety seven percent of illiterate women had $\geq 2$ children, as compared to $80 \%$ and $46 \%$ among women with $1-5$ years of schooling and $>5$ years of schooling respectively (chi square test for trend $\left.\chi^{2}=27.7 ; \mathrm{p}<0.001\right)$. Only 3\% of illiterate women had a single child, as compared to $20 \%$ and $54 \%$ among women with $1-5$ years of schooling $>5$ years of schooling respectively (chi square test for trend $\chi^{2}=25.2$; $\mathrm{p}<0.001)$. As the literacy of women increased, the number of children they had i.e., parity decreased.

\section{DISCUSSION}

This study was designed to understand the knowledge and practices of women regarding family planning methods in a rural setup in southern India. With the widespread provision of government's family planning services, this study was in an ideal position to measure its effect. Although this was a facility based study, the Primary Health Centres are located within the communities with welldefined catchment areas. People from lower socio-economic classes are more likely to utilise PHC services, hence the study participants are likely to be reasonably representative of the lower socio-economic classes of the community. This section forms a more vulnerable group in terms of requirement for family planning services, necessitating a better understanding of their behaviour.

The contraception prevalence rate among the study participants was $60 \%$ which is comparable to $64 \%$ reported in the national District Level Household and Facility Survey (DLHS)-3 (2007-08). ${ }^{3}$ Even though these women were selected from a health facility two fifths of them were not using any form of contraception, this is a potential opportunity missed for sensitising these women for adoption of contraceptive methods. Steps to ensure that this opportunity is better utilised to promote further contraception usage need to be devised. The prevalence of female sterilisation among those having two or more children was nearly $70 \%$, whereas the overall prevalence was $48 \%$ compared to the $37 \%$ reported in the National Family Health Survey (NFHS)-3 (2005-06). ${ }^{4}$ Since the participants were recruited in a health facility, their greater contact with health care services and greater awareness might be the reason for such high prevalence. This reflects considerable success for the health facilities in terms motivating women to adopt sterilisation as a means of contraception.

Literacy was positively associated with family planning related knowledge and practices. More literate women had satisfactory FPK than illiterate women; contraception was used by more literate women than illiterate women as also shown by Kunwar et $a .^{5}$ and more literate women

\begin{tabular}{|c|c|c|c|c|c|}
\hline No. & Variable & $\begin{array}{c}\text { Total } \\
\%(95 \% \mathrm{Cl})\end{array}$ & $\begin{array}{l}\text { Literate Nos. } \\
(\%)\end{array}$ & $\begin{array}{l}\text { Illiterate Nos. } \\
(\%)\end{array}$ & p value* \\
\hline 1 & Women who have satisfactory FPK & $59.0(49.2,68.1)$ & $54(86)$ & $2(5)$ & $<0.001$ \\
\hline 2 & $\begin{array}{l}\text { Proportion of women who have used or are currently } \\
\text { using contraception (any method) }\end{array}$ & $60.0(50.2,69.1)$ & $34(54)$ & $16(43)$ & 0.008 \\
\hline 3 & $\begin{array}{l}\text { Proportion of women who had undergone sterilization } \\
\text { among those with } \geq 2 \text { children }(n=70)\end{array}$ & $68.5(57.0,78.2)$ & $32(94)$ & $16(44)$ & $<0.001$ \\
\hline 4 & $\begin{array}{l}\text { Proportion of women who have undergone atleast one } \\
\text { abortion }\end{array}$ & $80.0(71.1,86.7)$ & $50(79)$ & $30(81)$ & 0.042 \\
\hline 5 & $\begin{array}{l}\text { Proportion of women who have undergone uncertified } \\
\text { abortion among those who have undergone } \\
\text { abortions }(n=80)\end{array}$ & $21.2(13.7,31.4)$ & $5(10)$ & $12(40)$ & 0.001 \\
\hline 6 & $\begin{array}{l}\text { Proportion of women who said they would prefer to have } \\
\text { male child }\end{array}$ & $59.0(49.2,68.1)$ & $32(51)$ & $27(73)$ & 0.029 \\
\hline
\end{tabular}


opted for sterilisation, similar to that reported by Sedlecki et al. ${ }^{6}$ As the literacy status of women increased the number children they had decreased, as was also reported by Adhikari R. ${ }^{7}$ and Hamadesh RR. et al. ${ }^{8}$ It is conceivable from a sociological viewpoint that educated women may have more control in decision making regarding family planning issues. This study provides evidence that a more distal factor like female literacy can greatly influence behaviour in a sustained favourable direction. It might not be sufficient to provide free contraception services alone but women must also be empowered with literacy for better utilisation of such services. This will contribute to long term success of the programme. Other distal factors that could promote greater adoption of contraception include women's economic empowerment and promotion of gender equity. ${ }^{9}$

In this study more illiterate women had a preference for male child as compared to literate women similar to that shown by Chen J. et al. ${ }^{10}$ Even so half of the literate women preferred a male child. This preference probably emerges from deep rooted social factors like patriarchal makeup of the society and problems of dowry. ${ }^{11}$ This issue requires concentrated efforts from various societal angles - law, civil society, health and family welfare, social justice and empowerment, education - to bring about a change in the attitude of society towards the girl child.

Nearly $80 \%$ of the women had ever undergone abortions, which is very high compared to $14 \%$ reported in NFHS-3. A very high proportion of both literate and illiterate women have undergone abortions. Induced abortions are an indicator of unmet needs for contraception. This high proportion may be due to the high prevalence of male child preference in both the groups which may lead to sex specific abortion, a prevalent practice in India. ${ }^{12}$ Further study is required to understand this unmet need for contraception so that appropriate interventions can be designed to reduce the abortion rate. It was observed that literate women were more likely to have undergone certified abortions as compared to illiterate women. Increased access to health facilities and knowledge about complications of unsafe abortion may be a probable explanation for this finding. This has a policy implication in the sense that measures to decrease the practice of uncertified abortions in rural areas will have to be urgently undertaken. This can be done by enhanced enforcement of the MTP Act (1971) and/or by devising a mechanism to train and incorporate traditional providers into the regular health system.
There are certain limitations in this study. Participants were selected by convenience sampling, hence the results cannot be generalised beyond the community studied. Significant associations found in this study might also be explained by confounding due to unmeasured variables like partner's literacy, family members' influence, influence of contact with peripheral health functionaries and other behaviour modifiers. Small sample size of the study also limits the generalizability of the results. Social desirability bias that is inherent in self-reported information cannot be ruled out while interpreting these results.

\section{CONCLUSION}

The contraception prevalence rate was satisfactory but further promotion of usage is required for timely realisation of national population goals. Promotion of literacy, especially female literacy and important distal factors like economic empowerment of women and gender equity is essential to bring about a social change for sustaining a successful family planning programme in this country.

\section{REFERENCES}

1. National Population Policy, 2000. National Commission on Population, Government of India. (Accessed on May 2, 2012, at http:// populationcommission.nic.in/npp.htm).

2. Prasad BG. Changes proposed in Social classification of Indian families. J Indian Med Assoc. 1970; 55: 198-9.

3. International Institute for Population Sciences (IIPS), 2010. District Level Household and Facility Survey (DLHS-3), 2007-08: India.Mumbai: IIPS.

4. International Institute for Population Sciences (IIPS) and Macro International. 2007. National Family Health Survey (NFHS-3), 2005-06: India: Volume I. Mumbai: IIPS.

5. Sedlecki K, Rasević M. Attitudes to voluntary sterilization in Serbia: women's and gynecologists' points of view. Eur J Contracept Reprod Health Care. 2006; 11(4): 277-84.

6. Kunwar S, Faridi MM, Singh S, Zahra F, Alizaidi Z. Pattern and determinants of breast feeding and contraceptive practices among mothers within six months postpartum. Biosci Trends. 2010; 4(4): 186-9.

7. Adhikari R. Demographic, socio-economic, and cultural factors affecting fertility differentials in Nepal. BMC Pregnancy Childbirth. 2010; 28: 10-19.

8. Hamadeh RR, Al-Roomi K, Masuadi E. Determinants of family size in a Gulf Arab state: a comparison between two areas. J R SocPromot Health. 2008; 128(5): 226-32.

9. Chen J, Xie Z, Liu H. Son preference, use of maternal health care, and infant mortality in rural China, 1989-2000. Popul Stud (Camb). 2007; 61(2):161-83.

10. Zelaya E, Marín FM, García J, Berglund S, Liljestrand J, Persson LA. Gender and social differences in adolescent sexuality and reproduction in Nicaragua. J Adolesc Health. 1997; 21(1): 39-46.

11. Myers, Christine (2012) "Sex Selective Abortion in India," Global Tides: Vol. 6, Article 3. (Accessed on May 2, 2012 at http://digitalcommons. pepperdine.edu/globaltides/vol6/iss1/3).

12. Jha P, Kesler MA, Kumar R, Ram F, Ram U, Aleksandrowicz L, et al. Trends in selective abortions of girls in India: analysis of nationally representative birth histories from 1990 to 2005 and census data from 1991 to 2011. Lancet. 2011; 377(9781): 1921. 